\title{
Research on the Influence and Application of New Media on the Film and Television Education in Colleges and Universities
}

\author{
Yuan Xue \\ Hebei University \\ Baoding, China
}

\begin{abstract}
With the arrival of all media era, the introduction of new media as a supplementary teaching means for the film and television education in colleges and universities is the necessity of the development of science and technology and the development of the times. This paper analyzes the advantages and disadvantages of the new media teaching methods on the teaching of film and television in colleges and universities, and focuses on the application of new media such as mobile phone and Internet to assist the teaching methods of film and television teaching in colleges and universities. It is pointed out that, while adopting new media teaching methods, strengthening the supervision and guidance of the process of film and television, and cultivate students to establish a healthy and noble aesthetic and values.
\end{abstract}

Keywords-new media; college film and television education; pros and cons; application strategy

\section{INTRODUCTION}

The new media, represented by portal websites, microblogs and mobile phone, is of great significance to the contemporary social life because of the rapid convenience of information dissemination, free from time and space, real-time interaction and so on. Film and television art as a popular audio-visual art and audio-visual touch of mobile phones, networks and other emerging media has a natural commonality and integration, the new media platform for college film and television teaching is the inevitable trend of scientific and technological progress and development of the times. College TV and television educators should give full play to mobile phones and networks and other new media medium in the auxiliary film and television teaching strengths, while strengthening Supervision and guidance in the process students collecting film and television information, guiding students in the use of new media to absorb film and television knowledge at the same time, establishing a healthy and full of positive energy of the aesthetic and values

\section{THE INFLUENCE OF NEW MEDIA ON THE ADVANTAGES AND DISADVANTAGES OF FILM AND TELEVISION EDUCATION IN COLLEGES AND UNIVERSITIES}

\section{A. The New Media on the Favorable Impact of Film and Television Education in Colleges and Universities}

1. The rational use of the new media platform for college teachers and students can greatly improve the interaction between teachers and students. Today's college students are contact with the Internet, e-mail and animation grew up in the "electronic generation", having a high tolerance and sensitivity to the new media. After the classroom teaching, teachers engaged in film and television education can get on dialogue and communication with students by using network, mobile phones and other new media medium cleverly and flexiblely. New media of real-time, virtual, interactive media characteristics make the teachers and students get the dual subject identity at the same time with the information transmission and reception of equal democracy and no barriers, facilitating the college film and television education for the part , personalized teaching, is conducive to the implementation of the concept of teaching students.

2. The new media will be compatible with the integration of text, images, voice and video and other elements of transmission, beyond the time and space constraints, to achieve fission-type transmission for the university film and television education to provide a wealth of diverse teaching resources, and promote the teaching content and technology innovation. For teachers, the new media provide information-intensive, quick and timely, real-time film and television creation of the latest information from the teaching content layout for the film and television teaching, which greatly improve the efficiency and quality of teachers' lesson preparation from the teaching content arrangement, the teaching section design to the case collection, teaching methods and so on, so that film and television teaching and the development of the film and television practice to echo, to avoid falling into the narrow knowledge, technology obsolete of the stereotypes. 
B. The New Media on the Disadvantages Impact of Film and Television Education in Colleges and Universities As A Auxiliary Teaching Means

1. The new media as an auxiliary means introduced in film and television teaching also have some drawbacks needed to be given full attention. Mobile phones, networks and other new media spread the message in a way of audio-visual touch and very interesting which students can get easily with no limit from time and space, making a challenge to classroom teaching of the subjectivity and voice. Some students too indulge in the varied loud noise of the massive information, played down the interest in the teaching of film and television classroom, from the personal interest. In addition, the large media coverage and real-time updates provided by new media also increase the difficulty of teachers in monitoring the reception of film and television information. If these massive messages do not be filtered, regulated and guided, the effect of new media-assisted film and television teaching is difficult to be guaranteed.

2. The new media as an auxiliary means introduced in film and television teaching is also easy for college students to have a negative impact on mental health. College students are adolescent , their mental state has its stage characteristics, such as susceptible to external factors, learning purpose is not strong, with reversal mind, lack of understanding and judgment of social complexity. Especially in the current new media communication environment, all kinds of film and television information can be obtained anytime, anywhere, surrounded by these massive information, young students are very interested in betting on those new and interesting film and television messages, lack of rational knowledge in the screening of these information, refining and reflection, vulnerable to the induction of bad information and go astray. In addition, through the new media to capture the convenience of film and television resources is also easy to promote the speculation of some students, provides an opportunity for plagiarism. Individual poor self-control students directly download the relevant information from the network as their own academic results, which directly have an impact on the quality of film and television teaching.

\section{THE APPLICATION STRATEGY OF COLLEGE FILM AND} TELEVISION TEACHING IN THE AUXILIARY OF THE NEW MEDIA

\section{A. The Flexible Application of Mobile Media in the Film and Television Teaching.}

Mobile phone has become a powerful film and television classroom auxiliary wing with its real-time convenient, flexible and powerful media function. Mobile phone as the carrier of the WeChat public number, self-timer, video and other functions of help platform for the film and television, playing a strong role in promoting students to practice film and television training techniques. For example, in the teaching of film and television in the "Scene and the picture composition", the teacher can prompt students in the spare time to take mobile or DV as a tool, from the surrounding living environment framing, repeatedly practice and really feel the characteristics and differences of vision, panoramic, medium shot, close shot and a close-up of these five kinds of scene. Taste and try to figure out the symmetrical composition, horizontal composition and other composition of the different framing angle and shooting techniques, through the perceptual experience after school practice, deepen the understanding of classroom theoretical knowledge. The pictures or the works or micro-video taken by students can be arranged for playing in classroom for teachers and students to observe the comments, to promote students progress and improvement.

WeChat public number as the new media social platform rose in recent years has a large user base, welcomed by much of the community. According to a study published in November 2016 by iiMedia Research, the number of WeChat public numbers in China in 2016 has exceeded 12 million, an increase of $46.2 \%$ over 2015 . WeChat public's impact on young students cohesion and guidance force can not be ignored with its powerful current information real-time push function. In the teaching of film and television professional in colleges and universities, the teaching and research group can create the exclusive micro-public number for the teachers and students of film and television, real-time release and timely update the professional knowledge, focus topics and commentary articles related to film and television teaching. Carefully designed content sections, features columns and text typesetting and so on for the students point of interest and acceptance .Discourse style as far as possible using lively and Smart, in line with the characteristics of contemporary youth expression language, and complement with classroom teaching professional language each other, supplemented by dynamic pictures and appropriate audio and video and text to match, enhance students' reading and accepting interest. For example, set "weekly sharing", "monthly recommendation" and other columns for students in the WeChat public number to recommend the latest film and television bibliography and commentary articles, while focusing on the timely update of platform content. In addition, you can also establish a teacher and student micro-credit group to "punch card sign" approach, will be related to film and television professional news, pictures, audio and video realtime push out, teachers and students between the exchange of information, teachers online answering questions and Inspire and encourage students' learning feeling.

\section{B. The Diversified Teaching Approach Based on the Internet}

According to China's Internet Center in January 2016 released the 37th "China Internet Development Statistics Report", as of December 2015, the number of Chinese Internet users has reached 688 million, and 10-39 age group of national groups reached $75.1 \%$, The Internet on the contemporary society, especially the great influence on young people can be seen. Including the microblogging, blog, video site, BBS forum and many other new media medium platform for the university film and television teaching provides a huge amount of film and television teaching resources, and the impact on the content setting of college film and television teaching, teaching methods can not be ignored. Teachers and students can be based on teaching requirements or personal interest learning from the portal to collect and watch different types, different countries and age of film and television works and related information, broaden the students' vision and access to film and television knowledge channels, providing convenience in practicing "flip classroom". For example, in the "montage" as 
the teaching content of the flip classroom teaching, the teacher pre-left thinking questions of "montage divided into what categories and representative works synecdoche", before the class students independently search for relevant text and image data. In the course of classroom teaching, teachers organize students to discussions in group, and speak by the group representatives in turn, supplemented by their own production of pictures or video, intuitively display and describe the different types of montage and its representative film fragments. Other groups can ask questions and discuss, and finally by the teacher comments and $\mathrm{Q} \& \mathrm{~A}$. In the pre-class preview and video production of these students self-learning links, the Internet covers a huge video resource library such as Youku, potatoes and other video-on-demand software for students to self-inquiry learning provides a strong support, that compared with the previous students only from the school library, college audio and video materials outside the books, CDs, DVD and other old learning methods, is no doubt more advanced convenience, and can greatly improve the efficiency of students learning.

the e-mail, QQ group, microblogging and learning forums and other various forms, flexible media based on network technology is the interaction platform between teachers and students to communicate, can make the teaching effect significantly improved. For example, most of the courses in Peking University's major film and television programs have opened a dedicated public e-mail. Instructors will send teaching materials such as teaching courseware and bibliography to public e-mail for students to download, and provide great convenience for students to review course content and submit assignments. In addition, teachers should encourage students to practice DV, digital cameras, mobile phones and other digital products to practice shooting and production of video skills in the spare time, students can upload their works to the relevant website or participate in micro-film contest, accept the public comments and scoring, From which to examine and reflect on their own gains and losses, strengths and weaknesses, accumulated experience, access to film and television creative skills and ideas of progress. Teachers can also set up teaching QQ group, in addition to publishing and curriculum related to the announcement, sharing film and television information, to submit student operations and other functions, the teachers and students in the QQ platform real-time interactive exchange of content on the class, such as film and television works of art, Shooting techniques and their social impact .As members of the QQ group can use the alias registration, across the identity barriers, so this kind of anonymous exchanges between teachers and students more democratic, frank and open. South China Normal University scholar Hu Qin Tai and others from the user threshold of the popular, the transmission efficiency was radiation geometric progression and other aspects confirmed that microblogging in the auxiliary teaching is indeed feasible. At present, some colleges and universities' film and television teaching teams create a dedicated microblogging, blog and learning forum, illustrations, set audio and video in one, to provide students with the latest learning materials and professional advice, upload high-quality film review articles, entering the competition, in a variety of ways to mobilize the enthusiasm of students. For example, the Ministry of Education, Humanities and Social Sciences key research base - China Communication University Radio and Television Research Center opened Sina microblogging, promote the latest film and television publishing news, overseas college students doing classroom notes skills and domestic and foreign experts of the lectures and other real-time information related to film and television professional for the relevant professional college students. Some experts and scholars have also opened a personal microblogging and blog, publish their own academic trends and teaching experience, students can use the network name to participate in the comments or praise, forward the wonderful content, teachers and students to make full use of spare time to complete the film and television Analysis and digest of certain knowledge points in professional field.

\section{Film and Television Educators Should Strengthen the} Screening and Supervision of Information Disseminated by New Media, Training Students to Establish A Healthy and Noble Aesthetic and Values

Film and television educators should give full play to the advantages of new media teaching, and strengthen the screening and supervision of new media teaching media, screen and filter of new media transmission of information may have a negative impact on the student's knowledge structure and mental health section. On the one hand, the supervision mechanism of the new media information requires the relevant departments of the society such as operators to strengthen the audit of the new media platform to prevent the spread of anomie information to create a healthy and civilized media public opinion environment. Colleges and universities can set up a new media public opinion supervision group, which regulates and supervises school's portal, BBS forum operation and information dissemination. Film and television professional teachers in the classroom recommend classic film and television works and excellent quality of the formal video site for students, after class interaction with students by WeChat public number, microblogging, QQ group, that students' learning feedback to be allocated and guided, while regularly organize a questionnaire about new media learning, and understand the students' learning situation and real feelings, finding the problems and bad tendencies and timely resolve it. For example, if there are students landing bad sites and forums, or in the selection of films appear biased, teachers can be targeted to correct the rectification, urging students to establish legal ethical concepts of the use of information in a new media environment, and select and refine the benefit information of professional learning messages that transmitted by new media, consciously resist the infiltration of bad information. Teachers should guide and inspire students in the "Internet + " era to improve the subject of speculation, correctly treat the relationship of personal choice and social norms from the perspective of positive psychology, and guide them to pay attention to those who promote the truth the good and the beautiful, highlight the socialist core values, the film and television masterpiece which can edify sentiment, purify the soul, establishing a healthy and noble aesthetic and values.

MOOC is a open education platform carried by the new media, the teachers mainly disseminate information to the public through the short topic of teaching video and e-mail, 
etc..The content of the video is rich and varied, and learners can choose the content of the course according to the individual learning needs, and can communicate with the instructors through various channels such as the official forum area, blog, micro public address and so on. At present, MOOC has entered the field of higher education in China, the "Austrian Peng Distance Education Center" under charge of the Ministry of Education and Peking University, Beijing Normal University, including dozens of colleges and universities set up a "MOOC" China Union. But MOOC also has its limitations, those courses which need auxiliary knowledge background and practical ability only relying on video and network evaluation system is unable to achieve the teaching effect. For example, students need to personally practice shooting and editing skills of film and television courses, MOOC can not fully meet their teaching requirements.

\section{CONCLUSION}

In short, the film and television educators should flexibilely select new media teaching methods, give full play to the new media teaching platform's strengths, to avoid its negative effects, promote improvement and innovation of film and television teaching content, technology and ideas. With the arrival of the era of the whole media the new media's teaching method's beneficial role in college film and television education in teaching practice will continue to be confirmed of which mobile phones and networks are the representative.

\section{REFERENCES}

[1] Qiu Xiaomei.The Influence and Countermeasures of New Media on Young College Students[J].Labor Security World, 2015, 23th.

[2] Hu Qintai, Lin Xiaofan.Research on the Construction of Social Education Communication Model Based on New Media[J].E-education Research, 2014, 5th.

[3] Wang Wanyao.Problems and Strategies of Film Education in Colleges and Universities in the Context of New Media[J].Film Review, 2013, 9th.

[4] Zhang Xiaoping.Ability and Wisdom[J].Research On the Influenceand Countermeasures of New Media on the Education of College Students' Socialist Core Values, 2015,01th. 